\title{
Current data on Covid-19 vaccine in pediatrics
}

\author{
Lalitphat Treerattanapun ${ }^{1,2}$, Preecha Montakantikul1* \\ 1 Department of Pharmacy, Faculty of Pharmacy, Mahidol University, Bangkok, Thailand \\ 2 Pharmacy Department, Faculty of Medicine Siriraj Hospital, Mahidol University, Bangkok, Thailand
}

\begin{abstract}
To date, COVID-19 has infected more than 200 million people worldwide, with 4 million having died because of it. The infection rate among pediatrics was $14.2 \%$ of the total COVID-19 cases. One of the effective tools for stopping this pandemic is the provision of SARS-CoV-2 immunity via vaccination. Many platforms have been developed in efforts to make the best SARS-CoV-2 vaccine. Most clinical studies confirmed their safety and efficacy in adults. However, we cannot guarantee that the immunogenicity and safety results of vaccines against SARS-CoV-2 in adults are the same for children. There are only 3 studies on the use of SARS-CoV-2 vaccines in children. Two mRNA-based vaccines have been approved for emergency use in children aged 12 years or older. The Pfizer-BioNTech COVID-19 vaccine, an mRNA-based vaccine, was the first COVID-19 vaccine authorized by the U.S. Food and Drug Administration for the prevention of COVID-19 disease in people aged 16 and older. In addition, 2 inactivated vaccines have been approved for use on children as young as 3 years of age. To date, 4 SARS-CoV-2 vaccines have been approved for use in children. However, data on the efficacy and safety of SARS$\mathrm{CoV}-2$ vaccines in children under 12 years of age are scarce. Studies on the long-term safety of the use of these vaccines in children is urgently needed.
\end{abstract}

\section{Keywords:}

SARS-CoV-2 vaccine, COVID-19 vaccine, Pediatrics

\section{INTRODUCTION}

The emergence of SARS-CoV-2 was the cause of acute respiratory infection known as COVID-19. The virus has spread rapidly around the world. The World Health Organization (WHO) estimated that there have been over 200 million infected patients and 4 million deaths worldwide. A joint report from the American Academy of Pediatrics and the US-based Children's Hospital Association stated that the SARS-CoV-2 infection rate in children was $14.2 \%$ of the total COVID-19 cases, and the mortality rate was $0.3 \%{ }^{1}$. Most children infected with COVID-19 are asymptomatic or have mild symptoms. However, about 10\% develop severe symptoms, need oxygen support, and are admitted to critical care units $^{2}$. There is some evidence of an association between COVID-19 and multisystem inflammatory syndrome in children $^{3}$. This phenomenon accounted for $1 \%-2 \%$ of the pediatric mortality rate ${ }^{4}$. Even though children infected with SARS-CoV-2 may be asymptomatic or have mild symptoms, they can still spread the virus to others, and they may develop multisystem inflammatory syndrome after the infection. Vaccination is the hope for reducing the rates of infection, transmission, and mortality. At present, many laboratories are developing SARS-CoV-2 vaccines. However, most of the studies on their protective efficacies, immunogenicities, and safety profiles were conducted on adults. There is still limited information relating to the pediatric population. Therefore, this article is a compilation of the published studies addressing the efficacy and safety of the use of SARS-CoV-2 vaccines in children. We searched PubMed and Google Scholar for information on platforms SARS-CoV-2 vaccines, and clinical studies on the effectiveness and safety of SARS$\mathrm{CoV}-2$ vaccines in pediatrics. We also reviewed ongoing trials listed in clinicaltrial.gov as well as the latest information on approved emergency usage available from the U.S. Centers for Disease Control and Prevention, WHO, and news sources.

\section{*Corresponding author:}

*Preecha Montakantikul preecha.mon@mahidol.ac.th 


\section{PLATFORMS FOR SARS-CoV-2 VACCINES}

When viruses invade the human body, the immune system produces several substances to fight off infection. The innate immune response to a SARS-CoV-2 infection involves an increase in neutrophils, serum interleukin 6 (IL-6), and C-reactive protein, as well as a reduction in lymphocytes. Researchers found that the degrees of the increase in the neutrophil numbers and of the reduction in the lymphocyte levels correlated with the severity of COVID-19 and death. Moreover, intensive care unit patients had high plasma levels of many innate cytokines, interferon gamma-induced protein 10 (IP-10), monocyte chemoattractant protein 1 (MCP1), macrophage inflammatory protein-1alpha (MIP-1A), and Tumor necrosis factor $\alpha(\mathrm{TNF} \alpha)$. Type I interferons produced by the innate immune system are effective mediators against viral infection, in that they control viral replication and induce an effective adaptive immune response ${ }^{5}$. Understanding the adaptive immune response of the human body to SARS-CoV-2 can help us produce vaccines to prevent infection.

In viral-infected patients, the T-cell dependent pathway stimulates the production of memory B cells. Research on the humoral immune response of patients with severe acute respiratory syndrome (SARS) found that the SARS-CoV infection induced seroconversion around 4-14 days after onset of the disease ${ }^{6}$. This contrasted with the 2-3 week period for seroconversion for Middle East respiratory syndrome coronavirus (MERS$\mathrm{CoV}$ ) infections ${ }^{7}$. Specific IgG and neutralizing antibodies are reported as long as 2 years after a coronavirus infection. A preliminary serological study of SARS-CoV-2 found 1 patient whose specific IgM response peaked on Day 9 after disease onset and switch to specific $\operatorname{IgG}$ response peaked on Day $14^{8}$. Other research on the T-cell response to a SARS-CoV infection found that a strong response was significantly correlated with higher levels of neutralizing antibodies ${ }^{9}$. Most responses $(70 \%)$ were found against the structural proteins (spike, envelope, membrane, and nucleocapsid) ${ }^{10}$. Many strategies were used to develop a SARS-CoV-2 vaccine based on a coronavirus vaccine which shares a high genetic similarity with SARS-CoV-2. The surface-exposed spike glycoprotein (or S protein) that swells outside the virion was the major target for the induction of neutralizing antibodies. The $\mathrm{S}$ protein molecule contains two subunits: S1 and S2. The S1 subunit has an S1-receptorbinding domain that interacts with the SARS-CoV-2 host-cell receptor, angiotensin-converting enzyme 2 . The S2 subunit mediates fusion between the virus and host cell membranes, thereby releasing viral RNA into the cytoplasm for replication. Consequently, S-protein based vaccines should induce antibodies that block both viral receptor binding and virus genome uncoating ${ }^{11}$.

To date, many platforms for SARS-CoV-2 vaccines have been developed and studied in clinical trials $^{8,12-13}$.

\subsection{Inactivated pathogen vaccines}

Whole viral pathogens that have been heated or inactivated by chemical treatment were introduced into the body. Hence, the immune response is directed against both the spike protein and many other SARSCoV-2 antigens. In other words, the dead antigens are used to produce antibodies which can fight the virus in future attacks.

The inactivated SARS-CoV-2 vaccines that are in Phase III trials and already approved for limited use by WHO are CoronaVac by Sinovac Biotech, and BBIBP-CorV by Sinopharm. Another inactivated vaccine is currently being considered for WHO Emergency Use Listing: Covaxin (BBV 152), by Bharat Biotech. The most common adverse reactions observed with inactivated SARS-CoV-2 vaccines were injection-site pain and fever. Both effects were mild and self-limiting.

\subsection{Subunit vaccines}

Subunit vaccines are prepared by purifying pathogenic viral antigen replicated in cell cultures or antigen recombinant. These vaccines commonly require the addition of adjuvant in order to be uptaken by antigen-presenting cells and stimulate adaptive immune responses. Two types of subunit vaccine are in the process of being developed as SARS-CoV-2 vaccines.

\subsubsection{Protein subunit vaccines}

Protein subunit vaccines can induce antibodymediated immunity with a weak induction of the T-cell response. This type of vaccine usually needs adjuvants to boost the immune response and increase vaccine efficacy. One candidate for a SARS-CoV-2 protein subunit vaccine is NVX-CoV2373. It is a full-length recombinant SARS-CoV-2 glycoprotein nanoparticle vaccine adjuvanted with Matrix $M$. It is presently undergoing phase 3 clinical trials.

\subsubsection{Virus-like particle vaccines}

Virus-like particles (VLP) are designed to mimic the virus structure. They can therefore trigger strong immune responses against the antigens presented on their surface. Due to the lack of a pathogen gene, their safety profile is good. One virus-like particle candidate for SARS-CoV-2 is Co-VLP. Developed by the Canadianbased Medicago Inc., it was made from spike protein aggregates in the form of virus-like particles, plus a GSK adjuvant. Co-VLP is undergoing phase 3 clinical trials. 
At the time of writing of this article, no protein subunit or virus-like particle SARS-CoV-2 vaccines had been approved by WHO.

\subsection{Viral vector vaccines}

Viral vector vaccines are made by inserting viral DNA into nonpathogenic adenovirus. Adenovirus vectors carry a DNA sequence that codes the full-length spike protein of SARS-CoV-2. The vectors present antigenic proteins to lymphocytes, which triggers the immune response.

There are many candidates viral-vector-based SARS-CoV-2 vaccines. However, as at the time of this review, only 2 vaccines were approved by the U.S. Food and Drug Administration for emergency use in the COVID-19 pandemic. Thromboembolic events have been reported for each vaccine. These may be related to adenovirus-platelet-leukocyte complexes formed after vaccination.

\subsubsection{AZD1222 (ChAdOxI nCoV-19)}

This vaccine is composed of a replicationdeficient chimpanzee adenoviral vector, ChAdOx1. It contains the full-length the of SARS-CoV-2 structural surface glycoprotein, with a tissue plasminogen activator leader sequence. It was jointly developed by the Oxford Vaccine Group and AstraZeneca. Adults older than 55 years can better tolerate this vaccine than younger adults.

\subsubsection{JNJ-78436735 (Ad26.COV2.S)}

This monovalent vaccine is composed of a recombinant, replication, incompetent human adenovirus serotype 26 ( $\mathrm{Ad} 26$ ) vector that encodes the SARS$\mathrm{CoV}-2$ virus spike protein. It was developed by Johnson \& Johnson.

\subsection{Nucleic acid vaccines}

A new approach to human vaccine development is the use of nucleic acid platforms that encode pathogen antigen. Once nucleic vaccines enter the human body, they create some of the virus's molecules. Nucleic vaccines are strong inducers. They stimulate not only $\mathrm{T}$ cell and $\mathrm{B}$ cell responses, but also the innate immune response. Nonetheless, DNA and mRNA are made from different steps of the production process, and they have different stabilities.

\subsubsection{DNA vaccines}

No DNA vaccines are currently approved for use in humans. However, they are currently used in veterinary fields, such as vaccines against West Nile
Virus in horses. As to a DNA vaccine against SARSCoV-2, the DNA circle containing the spike protein gene of the virus enters a nucleus and translates into mRNA. In turn, the mRNA translates into the SARS-CoV-2 spike protein, which presents on cell membranes.

\subsubsection{RNA vaccines}

Unlike a DNA vaccine, mRNA molecules need a good carrier to enable them to reach cytoplasmic or endoplasmic reticulum ribosomes in order to be translated into protein. The induction of the immune response is similar to that for a DNA vaccine.

The weak point of mRNA molecules is that their long-term storage requires very low temperatures. To deal with this problem, mRNA vaccines may add specific mutations and have stabilizing chemical modifications. Currently, 2 mRNA vaccines have been approved for use: mRNA-1273 and BNT162b2. There have been reports of myocarditis and pericarditis developing after the use of mRNA vaccines. These reactions tend to occur in young males (aged 18-24 years), and more usually after the second than the first dose. Nevertheless, the side effects are rare. They typically occur within 4 days of vaccination, but there have been longer periods in a few cases.

\section{SARS-CoV-2 VACCINES FOR PEDIATRICS}

The COVID-19 pandemic has effectively obliged all countries around the world to implement vaccination programs for their adult populations. However, there is a different situation for children and adolescents. Children can be divided into 2 groups: those aged 12 years or more, and younger children. In the case of the first group, the U.S. Centers for Disease Control and Prevention (CDC) and the American Academy of Pediatrics (AAP) recommend the administration of a SARS-CoV-2 vaccination for all children except those with contraindications. The organizations also advise that the children may be given a SARS-CoV-2 vaccine with other vaccines at the same visit, in other words, without a 14 days waiting period between the different vaccines $^{14-15}$.

In the case of children younger than 12 years, however, neither the CDC nor the AAP recommend that SARS-CoV-2 vaccines be given. This is because only limited clinical studies on the safety and efficacy of the vaccines are presently available. There are therefore many concerns, such as the influence of immune maturation and response, ethical issues, and the safety profile of SARS-CoV-2 vaccines ${ }^{16}$. Nonetheless, both China and the United Arab Emirates (UAE) have approved the use of inactivated SARS-CoV-2 vaccines in children younger than 12 years. These two countries will soon begin to provide these vaccines for children aged from 
3 to 17 years. To date, 4 SARS-CoV-2 vaccines have been approved for use in children (Table 1).

BNT162b2 (Pfizer-BioNTech) was the first SARS-CoV-2 vaccine approved by the U.S. Food and Drug Administration and the European Medicines Agency for use in children older than 12 years. The approval was given on May 10, 2021. This lipid-based, nucleoside-modified mRNA vaccine encodes the trimerized receptor-binder spike glycoprotein of SARSCoV-2. A clinical study of the vaccine's safety, immunogenicity, and efficacy in adolescents was conducted October 2020-January 2021. In all, 2260 healthy adolescents (aged 12-15 years) were randomly given BNT162b2 or a placebo. The results indicated that adolescents receiving 2 intramuscular injections of BNT162b2 (30 $\mathrm{mcg}) 21$ days apart experienced the same side effects as young adults (aged 16-25 years). The most common were pain at the injection site, fatigue, headache, muscle pain, and fever. The reactions were usually mild to moderate, and they typically improved within a few days. One month after receiving Dose 2 of BNT162b2, the geometric mean $50 \%$ neutralizing titer in adolescents was 1239.5 , which was greater than the corresponding value for the young adults (705.1). The study also found that the BNT162b2 vaccine had an efficacy of $100 \%$ against COVID-19 more than 7 days after the adolescents had received the second dose ${ }^{24}$.

Subsequent to the approval of the BNT162b2 vaccine, approximately six million doses have been administered in pediatrics aged 12 to 15 years. Safety studies have reported that the most common adverse events were pain at the injection site, fatigue, headache, myalgia, fever, nausea, and chills ${ }^{25}$. There were also case reports of myocarditis/pericarditis developing within 4 days of the second dose of BNT162b2 being given to seven 14 to 19 -year-old male adolescents. All 7 presented with chest pain, elevated troponin enzyme levels, and abnormal electrocardiogram, but no evidence of an acute SARS-CoV-2 infection. Six of the patients were treated with a nonsteroidal anti-inflammatory drug. Four of the patients were treated with intravenous immunoglobulin and oral prednisone; one of those four also received high-dose methylprednisolone ${ }^{26}$.

Shimabukuro examined the preliminary crude reporting rates of myocarditis and pericarditis following the administration of the BNT162b2 vaccine to 12 to $17-$ year-olds. The analysis revealed that the overall rates of the diseases at all doses was 18.1 cases per million doses. Moreover, higher rates of myocarditis and pericarditis were found in males than females. Most cases occurred after the administration of the second dose of the BNT162b2 vaccine ${ }^{25}$.

The mRNA-1273 vaccine (known as Moderna COVID-19 vaccine) has been approved for use in European pediatrics aged 12 years or older. It was approved for emergency use by the European Medicines Agency on July 23, 2021. This lipid-encapsulated, mRNA-based vaccine encodes a prefusion-stabilized form of full-length spike glycoprotein, S2P. In research on the use of mRNA1273 in 3732 healthy adolescents (aged 12-17 years), the vaccine demonstrated high efficacy in preventing COVID-19 and an acceptable safety profile. That study commenced in December 2020 and is still ongoing. The investigation found that the common side effects were pain at the injection site, headache, fatigue, chills, and fever. Those reactions mostly occurred after the second dose. They were also usually mild to moderate, typically improving in a few days. One month after receiving Dose 2 of the mRNA-1273 vaccine, the geometric mean $50 \%$ neutralizing antibody titer for 12 to 17 -year-old children was 1401.7. However, there was no significant difference from the corresponding value (1301) for

Table 1. Current status of SARS-CoV-2 vaccines approved for emergency use in pediatric populations (updated on September 30, 2021) ${ }^{(17-23)}$.

\begin{tabular}{|c|c|c|c|c|c|}
\hline Vaccine platform & Type of vaccine & Regimen & Sponsor & Approved age range & Status \\
\hline \multirow[t]{2}{*}{$\begin{array}{l}\text { RNA-based } \\
\text { vaccine }\end{array}$} & BNT162b2 & $\begin{array}{l}2 \text { doses, } \\
3 \text { weeks apart }\end{array}$ & BioNTech SE, Pfizer & $\geq 12$ years of age & $\begin{array}{l}\text { - Approved by FDA on May } \\
10,2021 \\
\text { - Fully approved by FDA on } \\
\text { August } 23,2021 \text { in people } \\
16 \text { years of age and older. } \\
\text { - Approved by EMA on May } \\
28,2021\end{array}$ \\
\hline & mRNA-1273 & $\begin{array}{l}2 \text { doses, } \\
4 \text { weeks apart }\end{array}$ & Moderna TX, Inc. & $\geq 12$ years of age & $\begin{array}{l}\text { - Approved by EMA on July } \\
23,2021\end{array}$ \\
\hline \multirow[t]{2}{*}{$\begin{array}{l}\text { Inactivated } \\
\text { vaccine }\end{array}$} & $\begin{array}{l}\text { Inactivated SARS- } \\
\text { CoV-2 vaccine }\end{array}$ & $\begin{array}{l}2 \text { doses, } \\
4 \text { weeks apart }\end{array}$ & $\begin{array}{l}\text { Sinovac Biotech Co., } \\
\text { Ltd. }\end{array}$ & $3-17$ years of age & $\begin{array}{l}\text { - Approved by China in June } \\
2021 \\
\text { - Approved by Chile in Sep- } \\
\text { tember } 2021 \text { ( } 6 \text { year old chil- } \\
\text { dren and older) }\end{array}$ \\
\hline & $\begin{array}{l}\text { Inactivated SARS- } \\
\text { CoV-2 vaccine } \\
\text { (Vero cell) }\end{array}$ & $\begin{array}{l}2 \text { doses, } \\
3 \text { weeks apart }\end{array}$ & $\begin{array}{l}\text { Beijing Institute of } \\
\text { Biological Products } \\
\text { (BIBP), Sinopharm }\end{array}$ & 3-17 years of age & $\begin{array}{l}\text { - Approved by China in July } \\
2021 \\
\text { - Approved by United Arab } \\
\text { Emirates in August } 2021\end{array}$ \\
\hline
\end{tabular}

EMA, European Medicine Agency; FDA, U.S. Food and Drug Administration 


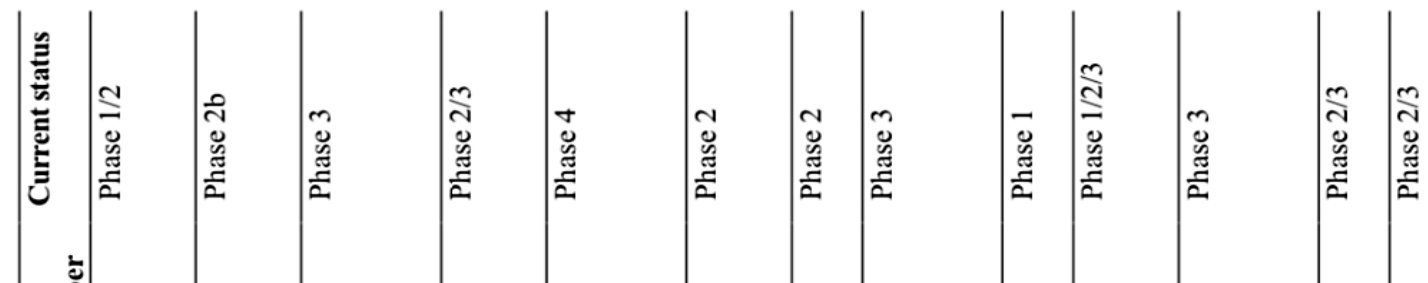

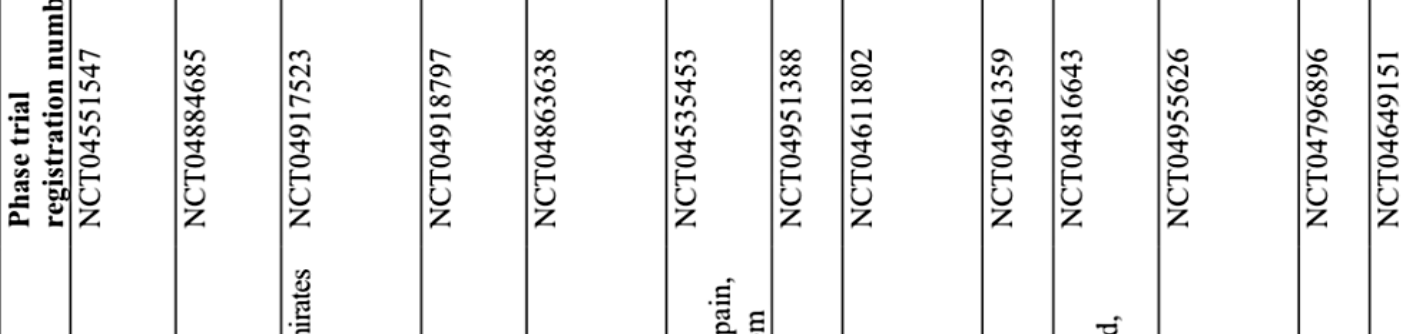

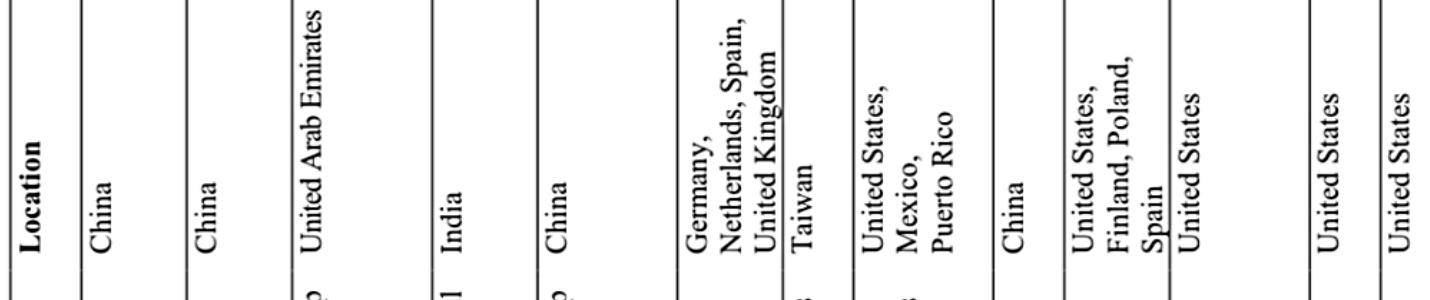
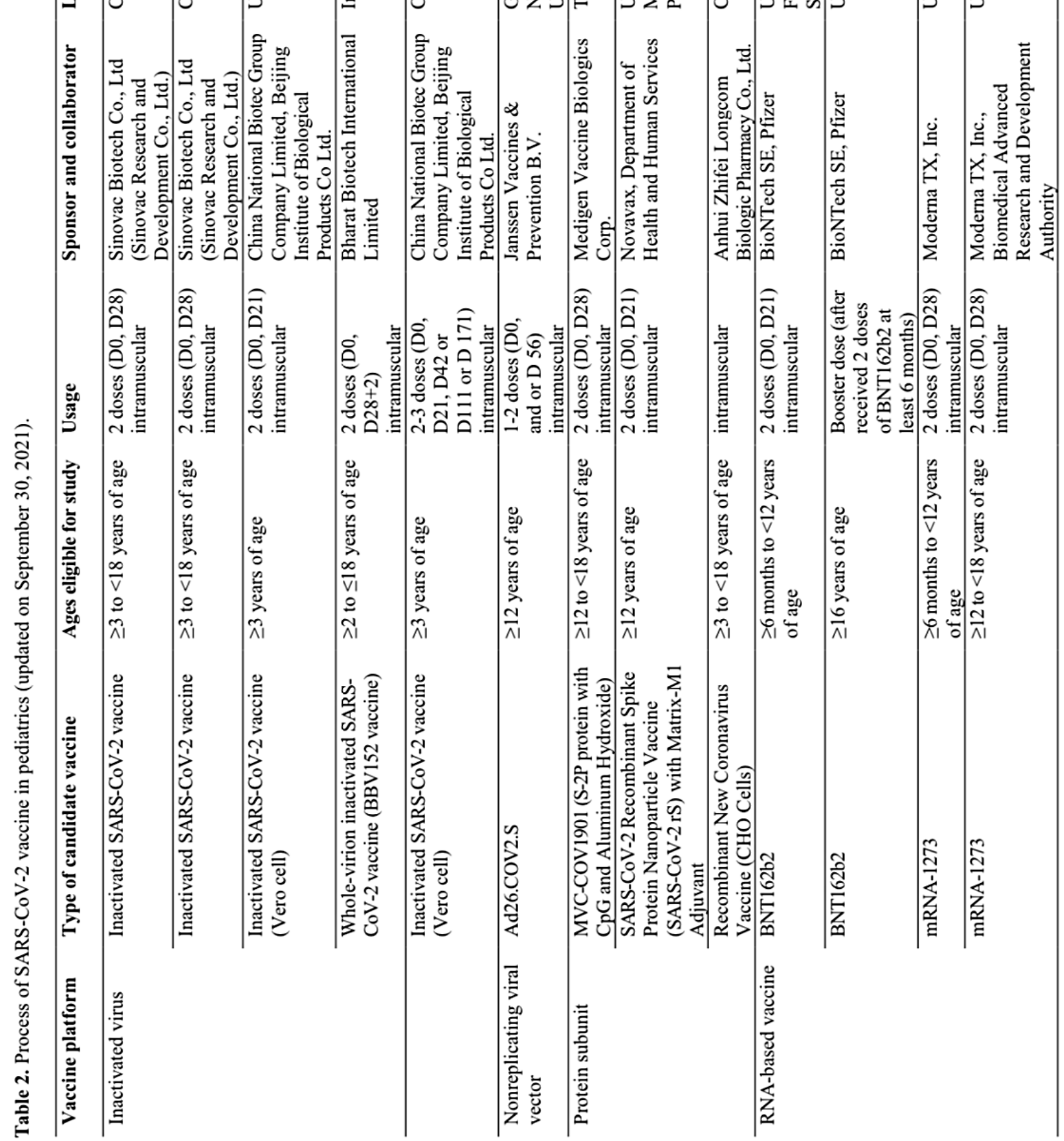
adults aged 18 to 25 years. An interim analysis of the research findings reported an efficacy of $93.3 \%$ for the mRNA-1273 vaccine 14 days after the 12 to 17 -year-old adolescents received their second injection ${ }^{27}$.

The CoronaVac clinical study investigated the use of SARS-CoV-2 vaccines in pediatrics younger than 12 years of age. This double-blind, randomized, controlled, phase $1 / 2$ clinical trial enrolled healthy children and adolescents aged 3 to 17 years in China. CoronaVac is an inactivated SARS-CoV-2 vaccine created from African green monkey kidney cells and inactivated with $\beta$-propiolactone. Aluminum hydroxide was added as an adjuvant. The research was conducted October 2020-December 2020. The participants were randomly assigned vaccine doses of $1.5 \mathrm{mcg}$ and $3.0 \mathrm{mcg}$ in $0.5 \mathrm{~mL}$ of aluminum hydroxide, and a placebo (aluminum hydroxide only). It was found that the neutralizing antibody titers for the $3.0 \mathrm{mcg}$ dose were higher than those for the $1.5 \mathrm{mcg}$ dose. The most common side effect was injection site pain and fever. Most adverse reactions occurred within 7 days and resolved within 48 hours $^{28}$.

Another clinical study examined the efficacy and safety of an inactivated SARS-CoV-2 vaccine, Sinopharm, developed by the Beijing Institute of Biological Products. However, the research results were not available at the time of writing.

There are many ongoing SARS-CoV-2 vaccine trials in pediatrics (Table 2).

\section{CONCLUSIONS}

Information on the safety and efficacy of SARS-CoV-2 vaccines for the pediatric population is still limited. Only 4 SARS-CoV-2 vaccines have been approved for use with pediatrics. According to the current research data, the youngest age approved for SARS-CoV-2 vaccinations is 3 years. The 2 vaccines that have been approved, Sinovac and Sinopharm, use an inactivated-pathogen platform. However, to date, only China and the United Arab Emirates have given emergency-use approval to the use of the 2 vaccines in children aged 3 years or older. The U.S. Food and Drug Administration has authorized an emergency use of the vaccine BNT162b2 in children aged 12 to 15 , and it has been fully approved for the prevention of COVID-19 disease in people aged 16 and older. Both BNT162b2 and mRNA-1273 have been approved for emergency use in children aged more than 12 years by the Committee for Medicinal Products for Human Use of the European Medicines Agency. Technically, BNT162b2 and mRNA1273 are mRNA-based vaccines; they must therefore be closely monitored, and further information on their long-term efficacy and safety is needed.

As to the other vaccine platforms, there are many ongoing clinical trials examining their efficacy and safety for the pediatric population.

\section{ACKNOWLEDGEMENT}

The authors thank Mr. David Park for English proofreading of the manuscript. This review did not receive any specific grant from funding agencies in the public, commercial, or not-for-profit sectors.

\section{Conflict of interest}

The authors declare that they have no conflict of interest.

\section{Funding}

None to declare.

\section{Ethics approval}

None to declare.

\section{Article info:}

Received August 24, 2021

Received in revised form October 3, 2021

Accepted October 25, 2021

\section{REFERENCES}

1. The American Academy of Pediatrics and the Children's Hospital Association. Children and COVID-19: State Data Report 2021 [document on the Internet]. The American Academy of Pediatrics; 2021[updated 2021 May 8; cited 2021 July 26]. Available from: https://downloads.aap.org/AAP/PDF/AAP\%20 and $\% 20 \mathrm{CHA} \% 20-\% 20$ Children $\% 20$ and $\% 20 \mathrm{COVID}-19 \% 20$ State \%20Data\%20Report\%208.5\%20FINAL.pdf.

2. Dong Y, Mo X, Hu Y, Qi X, Jiang F, Jiang Z, et al. Epidemiology of COVID-19 Among Children in China. Pediatrics. 2020; 145(6):e20200702.

3. Feldstein LR, Rose EB, Horwitz SM, Collins JP, Newhams MM, Son MBF, et al. Multisystem Inflammatory Syndrome in U.S. Children and Adolescents. N Engl J Med. 2020;383(4):334-46.

4. Kaushik S, Aydin SI, Derespina KR, Bansal PB, Kowalsky S, Trachtman R, et al. Multisystem Inflammatory Syndrome in Children Associated with Severe Acute Respiratory Syndrome Coronavirus 2 Infection (MIS-C): A Multi-institutional Study from New York City. J Pediatr. 2020;224:24-9.

5. Prompetchara E, Ketloy C, Palaga T. Immune responses in COVID-19 and potential vaccines: Lessons learned from SARS and MERS epidemic. Asian Pac J Allergy Immunol. 2020;38(1): $1-9$.

6. Liu W, Fontanet A, Zhang P-H, Zhan L, Xin Z-T, Baril L, et al. Two-Year Prospective Study of the Humoral Immune Response of Patients with Severe Acute Respiratory Syndrome. J Infect Dis. 2006;193(6):792-5.

7. Liu WJ, Zhao M, Liu K, Xu K, Wong G, Tan W, et al. T-cell immunity of SARS-CoV: Implications for vaccine development against MERS-CoV. Antiviral Res. 2017;137:82-92.

8. Zhou P, Yang X-L, Wang X-G, Hu B, Zhang L, Zhang W, et al. A pneumonia outbreak associated with a new coronavirus of probable bat origin. Nature. 2020;579(7798):270-3.

9. Li CK-f, Wu H, Yan H, Ma S, Wang L, Zhang M, et al. T Cell Responses to Whole SARS Coronavirus in Humans. J Immuno. 2008;181(8):5490-500.

10. Shin H-S, Kim Y, Kim G, Lee JY, Jeong I, Joh J-S, et al. Immune Responses to Middle East Respiratory Syndrome Coronavirus During the Acute and Convalescent Phases of Human Infection. Clin Infect Dis. 2018;68(6):984-92. 
11. Dhama K, Sharun K, Tiwari R, Dadar M, Malik YS, Singh KP, et al. COVID-19, an emerging coronavirus infection: advances and prospects in designing and developing vaccines, immunotherapeutics, and therapeutics. Hum Vaccin Immunother. 2020; 16(6):1232-8.

12. Kyriakidis NC, López-Cortés A, González EV, Grimaldos AB, Prado EO. SARS-CoV-2 vaccines strategies: a comprehensive review of phase 3 candidates. NPJ Vaccines. 2021;6(1):28.

13. Zahid MN, Moosa MS, Perna S, Buti EB. A review on COVID19 vaccines: stages of clinical trials, mode of actions and efficacy. Arab J Basic Appl Sci. 2021;28(1):225-33.

14. Center for Disease Control and Prevention. COVID-19 Vaccines for Children and Teens. Center for Disease Control and Prevention; 2021[document in the Internet]. [updated 2021 July 23; cited 2021 July 26]. Available from: https://www.cdc.gov/coronavirus/2019-ncov/vaccines/recommendations/adolescents.html.

15. Committee on Infectious Diseases. COVID-19 Vaccines in Children and Adolescents. Pediatrics. 2021;148(2):e2021052336.

16. Cooper DM, Afghani B, Byington CL, Cunningham CK, Golub $\mathrm{S}$, Lu KD, et al. SARS-CoV-2 vaccine testing and trials in the pediatric population: biologic, ethical, research, and implementation challenges. Pediatr Res. 2021;90(5):966-70.

17. U.S. Food and Drug Administration. Coronavirus (COVID-19) Update: FDA Authorizes Pfizer-BioNTech COVID-19 Vaccine for Emergency Use in Adolescents in Another Important Action in Fight Against Pandemic 2021 [document on the Internet]. U.S.Food and Drug Administration; 2021 [updated 2021 May 10; cited 2021 July 26]. Available from: https://www.fda.gov/ news-events/press-announcements/coronavirus-covid-19-updatefda-authorizes-pfizer-biontech-covid-19-vaccine-emergency-use.

18. U.S. Food and Drug Administration. FDA Approves First COVID-19 Vaccine [document on the Internet]. U.S.Food and Drug Administration; 2021 [updated 2021 August 23; cited 2021 September 30]. Available from: https://www.fda.gov/news-events/ press-announcements/fda-approves-first-covid-19-vaccine.

19. European Medicines Agency. First COVID-19 vaccine approved for children aged 12 to 15 in EU 2021 [document on the Internet]. European Medicines Agency; 2021 [updated 2021 May 28; cited 2021 July 26]. Available from: https://www.ema.europa.eu/en/ news/first-covid-19-vaccine-approved-children-aged-12-15-eu.

20. European Medicines Agency. COVID-19 vaccine Spikevax approved for children aged 12 to 17 in EU 2021 [document on the Internet]. European Medicines Agency; 2021 [updated 2021 July 23; cited 2021 July 26]. Available from: https://www.ema. europa.eu/en/news/covid-19-vaccine-spikevax-approved-childrenaged-12-17-eu.

21. Global Times. China approves emergency use of Sinovac's COVID-19 vaccine for children aged 3-17 [document on the Internet]. Global Times; 2021 [updated 2021 June 5; cited 2021 August 14]. Available from: https://www.globaltimes.cn/page/ 202106/1225430.shtml.

22. Global Times. UAE approves use of Chinese Sinopharm COVID-19 vaccine for 3-17 age group [document on the Internet]. Global Times; 2021 [updated 2021 August 4; cited 2021 August 14]. Available from: https://www.globaltimes.cn/page/202108/ 1230498.shtml.

23. Xiaoyu W. Sinopharm vaccine approved to treat children, teenagers [document on the Internet]. China daily; 2021 [updated 2021 July 20; cited 2021 August 14]. Available from: http:// www.chinadaily.com.cn/a/202107/20/WS60f60b13a310efa1bd 662ea4.html.

24. Frenck RW, Klein NP, Kitchin N, Gurtman A, Absalon J, Lockhart S, et al. Safety, Immunogenicity, and Efficacy of the BNT162b2 Covid-19 Vaccine in Adolescents. New England Journal of Medicine. 2021;385(3):239-50.

25. Shimabukuro T. COVID-19 Vaccine safety updates 2021 [document on the Internet]. Center for Disease Control and Prevention; 2021 [updated 2021 June 23; cited 2021 August 12]. Available from: https://www.cdc.gov/vaccines/acip/meetings/downloads/ slides-2021-06/03-COVID-Shimabukuro-508.pdf.

26. Marshall M, Ferguson ID, Lewis P, Jaggi P, Gagliardo C, Collins JS, et al. Symptomatic Acute Myocarditis in Seven Adolescents Following Pfizer-BioNTech COVID-19 Vaccination. Pediatrics. 2021;148(3):e2021052478.

27. Ali K, Berman G, Zhou H, Deng W, Faughnan V, CoronadoVoges M, et al. Evaluation of mRNA-1273 SARS-CoV-2 Vaccine in Adolescents. N Engl J Med. 2021;385:2241-51.

28. Han B, Song Y, Li C, Yang W, Ma Q, Jiang Z, et al. Safety, tolerability, and immunogenicity of an inactivated SARS-CoV-2 vaccine (Corona $\mathrm{Vac})$ in healthy children and adolescents: a double-blind, randomised, controlled, phase $1 / 2$ clinical trial. Lancet Infect Dis. 2021;12(12):P1645-53. 